\title{
Pervasive refusal syndrome in autism spectrum disorder: Difficulties in diagnosis
}

\author{
UR Attygalle, LMEU Guneratne, MRS Jayasekara
}

\section{Abstract}

Pervasive refusal syndrome in those with autism spectrum disorder is a rare condition, with only a few cases reported worldwide. This report highlights the difficulties in diagnosis, when symptoms of pervasive refusal syndrome present in those already diagnosed with an austism spectrum disorder.

Key words: Pervasive refusal syndrome, autism

SLJ Psychiatry 2019; 10(1): 19-21

\section{Introduction}

Pervasive refusal syndrome is a rare childhood psychiatric condition. This was first described by Lask et. al., in 1991 (1). It is characterized by a profound and pervasive refusal to eat, drink, talk, walk and engage in any form of self-care (2), leading to marked reduction in quality of life. Although not yet included in the major psychiatric classifications, this condition has gained interest in recent times. These children usually exhibit clear fluid refusal and weight loss, social withdrawal, social refusal, partial or complete refusal of two or more of the following, namely, mobilisation, speech and attention to personal care, active and passive resistance to acts of help and encouragement (2).

For pervasive refusal syndrome to be considered, the affected person should not have an organic condition, nor should another psychiatric disorder better account for the symptoms (2).

Females are more prone to develop pervasive refusal syndrome in comparison to males $(2,3)$. The mean age of presentation is around 10.5 years (2). The prognosis of pervasive refusal syndrome is generally good with a high rate of complete recovery (67\%) (3). However the process is described as 'painfully slow,' with an average of 12.8 months before recovery (3).

A premorbid perfectionist personality and a sense of helplessness appear to play an important role in the etiology of this condition. Pervasive refusal syndrome can also show symptom overlap with many other psychiatric disorders. The causes are unclear but likely to be complex and multiple, associated with a sense of hopelessness (2).

Treatment usually requires a multidisciplinary approach and is characterized by patience, gentle encouragement and tender loving care $(3,4)$. To the best our knowledge, this is the first time this condition is being reported in a child with autism spectrum disorder (ASD), in Sri Lanka.

\section{Case Report}

The patient was a boy aged 12 years and 3 months. He had a preexisting diagnosis of autism spectrum disorder (ASD). He was attending a regular school and was capable of attending to his day to day activities. He presented to our clinic with a history of refusal symptoms for two months duration.

At the time of presentation the main symptoms were apathy, refusal to eat, weight loss, mutism, school refusal, refusal to engage in his personal care, and social withdrawal. He was also seen to be monotonously and repetitively drawing the same picture of the Lord Buddha.

There was a history of bullying at school, after which he had refused to go to school. When he occasionally did eat, he ate alone, and avoided other family members. He was also resistant when his parents tried to help.

Mental state examination did not reveal any psychotic symptoms. The child was also seen by a paediatric neurologist, and assessments and investigations revealed no neurological abnormality or catatonia. 
Treatment involved of a multidisciplinary approach, consisting of inputs from occupational therapy, community nursing, medical and psychiatric professionals. This required regular hospital visits, as well as family interventions. The mainstay of treatment was of a supportive nature. A low dose of the medication, namely sertraline, was also started.

Within several months he began to interact with others and the repetitive drawing became less frequent. He began to eat and drink, initially in small amounts, and gradually started to take full meals served at home. With time his pattern of refusing help gradually diminished. He also started to communicate with family members. Subsequently he made conversation with our clinic staff and returned to school.

\section{Discussion}

One of the main issues with pervasive refusal syndrome is the difficulty in diagnosis and the symptom overlap with other psychiatric disorders $(5,6)$.

Features of food refusal or selectivity, refusal to engage in activities of personal hygiene and mutism or a lack of communication with others may also be manifestations of ASD or depression, and need to be considered (7). However, the child in our case also manifested feature of refusing help and refusal in many other domains, which appeared to be the primary feature of his condition.

Another differential diagnosis would be obsessive compulsive disorder (OCD) (8). This is an egodystonic condition in comparison to the repetitive behaviors seen in ASD (9). In our patient, we could not elicit any egodystonicity associated with his repetitive drawings. However, eliciting egodystonicty is sometimes not possible in children, as their ability to understand and describe their emotions may be limited. The symptoms also responded to a combination of sertraline and supportive psychotherapy.

Thus the child in our case manifested features of ASD, together with some features to suggest OCD and depression, in addition to features of pervasive refusal syndrome.

There have been a few cases previously reported cases of pervasive refusal syndrome associated with with ASD internationally $(6,10)$. A case of a child with an established diagnosis of ASD, presenting with severe restriction of food and fluids, total mutism, school refusal, urinary and fecal incontinence and communicating solely through typing on an ipad was reported in the United Kingdom (6). As in in our case, the refusal symptoms were more in relation to the parents.
Another case has been reported of a 4 year old boy with a differential diagnosis of ASD or generic pervasive refusal syndrome. However, in that instance no prior or concurrent diagnosis of ASD was made (10). The children in both these cases, as well as our case, were male. Pervasive refusal syndrome is much more common in females, but ASD is more common in males.

The difficulties in identifying the symptoms of pervasive refusal syndrome, as different from the already established diagnoses was evident from our case. This has also been an important consideration in this condition not being included in the major psychiatric classifications [6].

\section{Acknowledgements}

We would like to acknowledge the support provided by the child's parents when writing this report.

\section{Conflicts of interest}

None declared

UR Attygalle, LMEU Guneratne, MRS Jayasekara, Teaching Hospital Karapitiya, Galle

Correspondingauthor: UR Attygalle

Email: udenaa@gmail.comm

https://orcid.org/0000-0002-8064-2817

\section{References}

1. Lask B, Britten C, Kroll L, Magagna J, Tranter M. Children with pervasive refusal. Arch Dis Child 1991; 66(7): 866-9.

2. Jaspers T, Hanssen GM, Van der Valk JA, Hanekom JH, van Well GT, Schieveld JN. Pervasive refusal syndrome as part of the refusal-withdrawal-regression spectrum: critical review of the literature illustrated by a case report. Eur Child Adolesc Psychiatry 2009; 18(11): 645.

3. Lask B. Pervasive refusal syndrome. Adv Psychiatr Treat 2004; 10(2): 153-9.

4. Nunn KP, Thompson SL, Moore SG, English M, Burke EA, Byrne N. Managing pervasive refusal syndrome: strategies of hope. Clinical Child Psychol Psychiatry 1998; 3(2): $229-49$

5. Von Folsach LL, Montgomery E. Pervasive refusal syndrome among asylum-seeking children. Clinical Child Psychol Psychiatry 2006; 11(3): 457-73. 
6. Bond EC, Oliphant RY. Pervasive Refusal Syndrome in Autistic Spectrum Disorder. Case Reports Psych 2018; 2018.

7. Ahearn WH, Castine T, Nault K, Green G. An assessment of food acceptance in children with autism or pervasive developmental disorder - not otherwise specified. Journal Autism Dev Disord 2001; 31(5): 505-11.

8. Krebs G, Heyman I. Obsessive-compulsive disorder in children and adolescents. Arch Dis Child 2015; 100(5): 495-9.
9. Chowdhury M, Rahman H, Mullick MS, Arafat SM. Clinical profile and comorbidity of obsessive-compulsive disorder among children and adolescents: a crosssectional observation in Bangladesh. Psychiatry J 2016; 2016: 9029630

10. Taylor S, Dossetor DR, Kilham H, Bernard E. The youngest case of pervasive refusal syndrome? Clin Child Psychol Psychiatry 2000; 5(1): 23-9. 